\title{
The Effect of Parental Consanguinity and Inbreeding in Hirado, Japan
}

\author{
IV. Fertility and Reproductive Compensation
}

\author{
WILliam J. SCHULL* ** \\ University of Michigan \\ Toshiyuk I Furusho \\ Tokyo Medical and Dental University \\ Manabu Yamanoto \\ Kyoto Prefectural University of Medicine \\ Hideyo Nagano \\ Kyushu University \\ ICHTTa KoMatsu \\ Tokyo Medical and Dental University
}

Received March 19, 1970

Summary. A census of Hirado, Japan in the summer of 1964 produced data on the reproductive performances of husbands and wives for 10,530 marriages where either the husband, the wife, or both were alive and residing in the city at the time of the census. Approximately one in every 6 of these marriages involves spouses who are biologically related to one another, and in some 10 per cent of marriages the husband, wife, or both are inbred. Analysis of the effects of length of cohabitation, socio-economic status, and consanguinity and inbreeding on total pregnancies, total livebirths, and "net fertility" (total livebirths minus non-accidental deaths in the first 21 years of life) revealed the following insofar as marriages contracted in the years 1920-1939 are concerned:

1. Total pregnancies and total livebirths were significantly increased with consanguinity, but "net fertility" was not when allowance is made for the role of socio-economic factors, and religious affiliation is ignored. The latter finding is thought to reflect the increased risk of death to liveborn children born to consanguineous marriages. Among Buddhists, the only religious group large enough to warrant separate analysis, total pregnancies, total livebirths and "net fertility" are all significantly and positively associated with parental relationship. However, the regression coefficient associated with "net fertility" is less than half the value associated with either total pregnancies or total livebirths.

2. Among non-farm marriages, all three measures of reproductivity were increased significantly with paternal inbreeding when religious affiliation is ignored or restricted to Buddhists. Among farm marriages, these measures were decreased but not always significantly

* This manuscript was completed during the tenure of a Deutsche Forschungsgemeinschaft Guest Professorship in the Institut für Anthropologie und Humangenetik of the University of Heidelberg.

** The support of U.S. Atomic Energy Commission Grant AT(11-1)-1552 is gratefully acknowledged. 
so. Tests of the significance of the differences between farm and non-farm groups were almost invariably significant. No simple explanation other than chance can be advanced for this finding.

3. Total pregnancies and total livebirths, but not "net fertility" increase significantly with maternal inbreeding among non-farm marriages; within farm marriages these three metrics also increase, but significantly so only in the case of total livebirths. It is suggested that on Hirado the increased reproductivity of the consanguineous marriage largely offsets the increased mortality among the issue from such unions, and thereby dampens the rate of elimination of deleterious genes and the loss of genetic variability.

Studies of the results of the marriage of related individuals have generally focussed upon the attributes of the offspring from such unions. Surprisingly few attempts have been made to measure the fertility of the consanguineous marriage, and even rarer are the investigations of the effects of maternal and paternal inbreeding upon fertility, however measured. Those few studies which have been conducted (see, for example, Schull, 1959; Tanaka et al., 1964) have invariably ignored the role of concomitant variability in fertility despite the accepted importance of socio-economic status, length and time of marriage, religion, and numerous other considerations which impinge upon a given couple's reproductive performance.

Data on the fertility of the consanguineous marriage have an importance to "load theory", particularly those efforts which rely upon the estimation of inbreeding depression in mortality and morbidity to evaluate the contribution of various mechanisms capable of maintaining genetic variability. But, in addition, they may contribute to the delineation of another mechanism of importance, particularly in human populations, in the maintenance of genetic variability, namely, "reproductive compensation". The latter has been commonly and simply defined as the replacement of a child that dies young. Fisher (1930, p. 158 et seq.), in a discussion of the influence of natural selection on the sex ratio, has suggested that the expenditure of energy is the pertinent parameter in assaying the reproductive performance of a family rather than the number of pregnancies, and that this expenditure of energy may be constant from mating to mating. This notion has been extended by Bodmer and Edwards (1960; see also Edwards, 1961). However, few genetic models incorporate this possibility, or even acknowledge that the relative fitness of a genotype (or phenotype) may vary with family size and composition. As Edwards (1961) has pointed out, the inclusion of "reproductive compensation" into gene frequency models leads to nonlinear recurrence relationships which often pose formidable analytical problems, but are presumably amenable to numerical analysis. Haldane and Jayakar $(1963,1965)$ have illustrated how some of these equations may be solved, and have also managed to show that in the case of selection for a single pair of alleles with complete replacement (the ultimate in reproductive compensation) a stable polymorphism is sometimes possible without greater overall fitness of the heterozygote. More recently, Feldman et al. (1969) have analyzed the role of reproductive compensation and heterozygote advantage in the maintenance of the Rh polymorphism through a method which has much broader potential applicability. Possibly further evidence of the occurrence of this phenomenon will serve as an added stimulus to explore some of the genetic issues involved. 
What, now, is required in a demonstration of reproductive compensation? Necessary and sufficient conditions for the existence of such compensation, complete or partial, are (1) differential mortality associated with specific phenotypes which segregate with different frequencies in different matings, and (2) equal or near equal net fertility of all families in spite of these mortality differentials. Clearly, the mortality must occur sufficiently early in life that further child-bearing is not precluded by the age of the husband and wife. Insofar as human populations are concerned, the existence of a culturally imposed norm of reproduction to which most if not all families strive, consciously or unconsciously, would be additional evidence. A rigorous case for genetically significant reproductive compensation in a particular instance is admittedly difficult to construct because of the numerous extraneous variables, largely of a socio-economic nature as previously stated, which can affect both mortality and reproductive performance.

This presentation is concerned with a study of the fertility of inbred individuals and consanguineous marriages on Hirado, and the possible occurrence of reproductive compensation in such marriages. The case to be exposed is circumstantial. In an earlier publication we (Schull et al., 1970) have established that in the locale of the present study, pre-reproductive mortality among liveborn children increases significantly with parental consanguinity, presumably as a consequence of homozygosity for sublethal and subvital genes. Thus, there is evidence of differential mortality, ostensibly associated with specific phenotypes segregating with different frequencies in different families. Is there a fertility differential which may be compensatory?

\section{The Study}

The data to be presented stem from a census of Hirado-shi in Japan initiated in June 1964 by a consortium of five universities - Juntendo University, Kyoto Prefectural University of Medicine, Kyushu University, Tokyo Medical and Dental University, and the University of Michigan. Broadly stated, the aims of this census or more properly the Hirado Health Survey of which this census was a part were the ascertainment of the fertility of the consanguineous marriage, the reproductive performance of the inbred individual, and certain observations on the children born to parents, especially mothers, who are themselves the products of consanguineous marriages. To avoid confusion here and subsequently we shall distinguish between consanguinity and inbreeding effects. The former expression will be restricted to the effect of a consanguineous marriage on the number of offspring of such a marriage; whereas the term inbreeding effect will be limited to those effects on offspring number which result from a parent being the product of a consanguineous marriage.

The census takers were generally either midwives or public health nurses, but on occasion, young physicians from the educational institutions previously mentioned. Birth date, birth place, education, occupation, religion, date of marriage (if married), consanguinity, and a pregnancy-by-pregnancy listing of the reproductive performances of the husband and wife were obtained by interview on every marriage where one or both spouses was alive and residing in Hirado at the time of the census. Additional data on number of persons in the household, the 
size of the house, diet, income, land holdings and attitudes toward reproduction were obtained on marriages involving household heads. The results of the interviews were regularly compared, where possible, with records of the koseki-ka, the agency of the Ministry of Justice charged with the custody of the koseki, the Japanese household censuses; the Public Health Office; the Tax Office; and the Agricultural and Fishing Cooperatives. Of particular concern was the accuracy of the information on consanguinity and inbreeding; a studied effort was made, therefore, to verify, through the appropriate loseki, statements with respect to consanguinity and inbreeding on all marriages contracted in the years $1920-1950$ inclusive. The choice of these years reflects two considerations. First, most marriages contracted subsequent to 1950 would not have completed reproduction in 1964, and we are primarily concerned with fertility in the completed family. Second, the koseki system was not instituted until the $1870 \mathrm{~s}$, and thus for marriages prior to 1920 it is frequently impossible to verify consanguineous marriages more remote than first cousins. Discrepancies, when they occurred, were resolved either by further interviewing, an appeal to other governmental records, or through the application of a sometimes arbitrary but uniformly (with respect to consanguinity and inbreeding) applied set of standards.

At the time of the census, Hirado was thought to have a population in excess of 40,000 persons (the 1960 Japanese census had revealed 40,881 inhabitants) distributed over some 8,200 households. All individuals then resident on the island or normally there were enumerated; this enumeration revealed the population to be some $10 \%$ smaller than the census figure just cited. The discrepancy undoubtedly reflects some differences in the definition of residence in this census as contrasted with the Japanese National Census, but also, like most predominantly rural areas of Japan, the population of Hirado is slowly declining. Hirado's inhabitants are primarily Buddhists, but there are also sizable groups of Roman Catholics and kakure kirishitan. The latter are members of a syncretic religion which incorporates elements of Buddhism, Catholicism, and Shintoism (a thorough account of this group is to be found in Tagita, 1954; see also Furuno, 1959). The existence of these different religious communities was known before the census, and in fact, was one of the reasons for the selection of Hirado as the study locale. It was conjectured that the different attitudes toward reproduction and consanguineous marriages which characterize these groups provided the basis for a "natural experiment".

Each of the religious communities is more or less socially isolated from the others, and relatively few mixed marriages exist. Consanguineous marriages occur within all groups, but the frequency and the kind of consanguineous unions which are encountered vary. Thus, some $27.2 \%$ of kakure marriages were consanguineous as contrasted with $14.6 \%$ of Buddhist marriages and $8.3 \%$ of Catholic unions. Moreover, $42.7 \%$ of the related marriages among the kakure involved first cousins; whereas among Buddhists, first cousins comprised $39.3 \%$ of the related marriages and even fewer, $6.9 \%$, of consanguineous Catholic marriages involved first cousins. Further details of the marriage practices on this island will be found in Schull et al. (1968).

Socio-economic variability is one of the more important potential contributors to the total variance in the number of offspring produced. Considerable effort was 
made, therefore, to record and quantitate the socio-economic variability which exists on Hirado. Our concerns were twofold. First, previous experience (Schull and Neel, 1965) suggested that socio-economic status might be dissimilarly distributed among consanguinity classes, as in fact it proved to be. Second, if the contemplated tests of significance were to be maximally sensitive, as much extraneous variability as possible, whether uniformly or non-uniformly distributed, had to be removed. As stated, significant socio-economic differences have been shown to exist among the farm and non-farm families of Hirado which are related to the occurrence of consanguineous marriage. Socio-economic standing, as judged by a socio-economic score based upon education, occupation, income, etc., improves with relationship of husband and wife when the husband is a farmer, but worsens when the husband is a non-farmer (Schull et al., 1970). This fact, though not unexpected, obviously introduced an added element of complexity into the analysis of the data.

To provide a perspective on the contribution of these various sources of variability to family size we shall routinely present three analyses. The first of these views reproduction as an additive function of length of cohabitation, the coefficients of inbreeding of husband and wife, and the biological relationship which obtains between these spouses, expressed as the coefficient of inbreeding of their issue, real or potential. No effort is made to remove the effects of socio-economic variables. The second analysis is restricted to those marriages where the husband is neither a farmer nor otherwise involved in agricultural pursuits (e.g., not an employee of the Agricultural Cooperative). Here, reproductive performance is assumed to be a function of length of cohabitation, consanguinity and inbreeding, and, in addition, socio-economic score. The third analysis is similar to the second but limited to farm families. Within these three alternatives, different time periods will be examined, as well as the data restricted to Buddhists (the Catholic and kakure data are too few to warrant separate analyses), and somewhat different regression models will be employed to describe the relationship of the "independent" variables cited to reproductive performance.

\section{Japanese Attitudes toward Reproduetion and Family Sizes}

There was enacted in Japan in September 1948 a law, the so-called Eugenics Protection Law, which legalized induced abortion under a wide variety of circumstances and the sterilization, generally voluntary but in some cases compulsory, of either husband or wife or both. Coincident with this development an educational campaign was mounted to inculcate into the Japanese a desire for smaller families. In the succeeding years, the law has been amended on several occasions, usually with a view toward further liberalization of its provisions. Within a very short period after its promulgation, the population trend of Japan changed dramatically - the birth rate fell from over 30 births per 1,000 population per annum to approximately half this value. The birth rate dropped so abruptly, in fact, that far less was learned about the process of change itself than would be desired in view of population trends in so many areas of the world. The magnitude and rate of the fall is documented, of course (see, for example, Taeuber, 1958), but little is known about possible social, economic, and geographical differentials within the 
country. It is generally accepted, however, that substantial urban-rural differences existed in the alacrity with which the provisions of the law were accepted.

To minimize the possible effects of this transition from a high birth rate to a low one, we shall regularly and separately examine those marriages revealed by the census to have occurred at such a time that their reproduction was wholly or at least largely completed before the effect of the Eugenics Protection Law was manifest. We shall also examine the totality of the data, since changes of social forms are an integral part of man's evolution, and their effects can not be burked. It should be noted that even if profound changes in fertility patterns have occurred, the present inquiry is compromised only insofar as the generality of the conclusions which may be drawn are concerned, and not in the relevance of these data to an appraisal of the present effects of inbreeding in the Japanese.

One of our first concerns was with attitudes toward artificial interruption of pregnancies, and the effects of religion, length of cohabitation, and the relationship of husband to wife upon such attitudes. Table 1 exposes some of the relevant data. Significant differences exist among the religious groups; Catholics view artificial interruption of pregnancy more unfavorably than do others although not all disapprove. The kakure are somewhat more favorably disposed, but less so than Buddhists. Some of this apparent religious difference is artifactual, however, and reflects a confounding of rural with religious attitudes. The majority of the Catholics and kakure are farmers; whereas a very substantial proportion of the Buddhists are engaged in other occupations. A truer picture of the difference in attitude emerges if attention is restricted to those Buddhists residing in Himosashi and Shishi machi, the areas in which most of the Catholics and kakure reside. Here the kakure are about midway in their attitude between Buddhists and Catholics, but even the Buddhists are appreciably more conservative in their response to the law than the totality of Buddhists. Maximum approval of artificial interruption of pregnancies among the Buddhists occurs not in the most recent marriages, but among those occurring in the 1940s and 1950s where the spouses have presumably achieved the families they sought. Note also that within religions marriages contracted in the years 1920-1939 have a more uniform attitude towards the appropriateness of the artificial interruption of a pregnancy than more recent marriages; this is an important observation in view of the special attention which is to be devoted to the reproductive performances of marriages which occurred in this span of 20 years. Finally, if these data are further subdivided on the basis of the relationship of husband to wife, there emerge no significant differences among the various degrees of relationship.

Somewhat more than 7,000 families, where marriage occurred in this century, responded to the request to state the number of children they felt to be most suitable. The results are set out in Table 2 . Overall, the average number of children considered desirable is 4.00 , but again important religious differences obtain. Mean desirable family sizes are 3.88, 4.66 and 4.27 for Buddhists, Catholics, and kakure, respectively; the group with the smallest mean, the "others", consists largely of individuals drawn from the more densely populated areas near the island's main harbor who identify themselves as Shinto, Christian but not Catholic, or without religion. Observe also the slowness with which these figures, surely culturally imprinted norms, change. Over a span of 64 years, mean desirable family size has 
Table 1. Attitudes toward the artificial interruption of pregnancies distributed by religion of husband and decade of marriage

\begin{tabular}{|c|c|c|c|c|}
\hline \multirow[t]{2}{*}{ Decade } & \multicolumn{4}{|l|}{ Attitude } \\
\hline & Approve & Disapprove & No Opinion & Total \\
\hline & \multicolumn{4}{|l|}{ All Buddhists } \\
\hline 1900 & $3(4.6 \%)$ & 58 & 4 & 65 \\
\hline 1910 & $42(8.9 \%)$ & 408 & 24 & 474 \\
\hline 1920 & $73(7.6 \%)$ & 852 & 41 & 966 \\
\hline 1930 & $97(8.4 \%)$ & 1002 & 55 & 1154 \\
\hline 1940 & $181(10.9 \%)$ & 1397 & 88 & 1666 \\
\hline 1950 & $133(12.2 \%)$ & 893 & 65 & 1091 \\
\hline 1960 & $23(7.1 \%)$ & 281 & 20 & 324 \\
\hline \multirow[t]{2}{*}{ Total } & $552(9.6 \%)$ & 4895 & 297 & 5740 \\
\hline & \multicolumn{4}{|c|}{ Himosashi-Shishi Buddhists } \\
\hline 1900 & $1(14.3 \%)$ & 6 & 0 & 7 \\
\hline 1910 & $2(3.0 \%)$ & 65 & 0 & 67 \\
\hline 1920 & $5(3.6 \%)$ & 133 & 2 & 140 \\
\hline 1930 & $5(3.1 \%)$ & 156 & 1 & 162 \\
\hline 1940 & $25(10.0 \%)$ & 225 & 1 & 251 \\
\hline 1950 & $8(5.0 \%)$ & 150 & 2 & 160 \\
\hline 1960 & $2(3.8 \%)$ & 50 & 1 & 53 \\
\hline \multirow[t]{2}{*}{ Total } & $48(5.7 \%)$ & 785 & 7 & 840 \\
\hline & \multicolumn{4}{|l|}{ Catholics } \\
\hline 1900 & 0 & 13 & 0 & 13 \\
\hline 1910 & 0 & 63 & 3 & 66 \\
\hline 1920 & 0 & 150 & 1 & 151 \\
\hline 1930 & 0 & 168 & 2 & 170 \\
\hline 1940 & $3(1.0 \%)$ & 283 & 4 & 290 \\
\hline 1950 & $2(1.0 \%)$ & 196 & 3 & 201 \\
\hline 1960 & $1(2.8 \%)$ & 34 & 1 & 36 \\
\hline \multirow[t]{2}{*}{ Total } & $6(0.6 \%)$ & 908 & 14 & 927 \\
\hline & \multicolumn{4}{|c|}{ kakure kirishitan } \\
\hline 1900 & 0 & 5 & 0 & 5 \\
\hline 1910 & 0 & 40 & 0 & 40 \\
\hline 1920 & $1(1.0 \%)$ & 101 & 0 & 102 \\
\hline 1930 & $3(3.0 \%)$ & 97 & 1 & 101 \\
\hline 1940 & $3(2.4 \%)$ & 120 & 4 & 127 \\
\hline 1950 & $4(5.5 \%)$ & 69 & 0 & 73 \\
\hline 1960 & $2(16.7 \%)$ & 10 & 0 & 12 \\
\hline Total & $13(2.8 \%)$ & 442 & 5 & 460 \\
\hline
\end{tabular}

declined from 4.12 to 3.38 children, and through much of the prewar period the change was negligible. Most of the change has occurred since World War II when the Japanese government initiated an active and successful program of population control. 


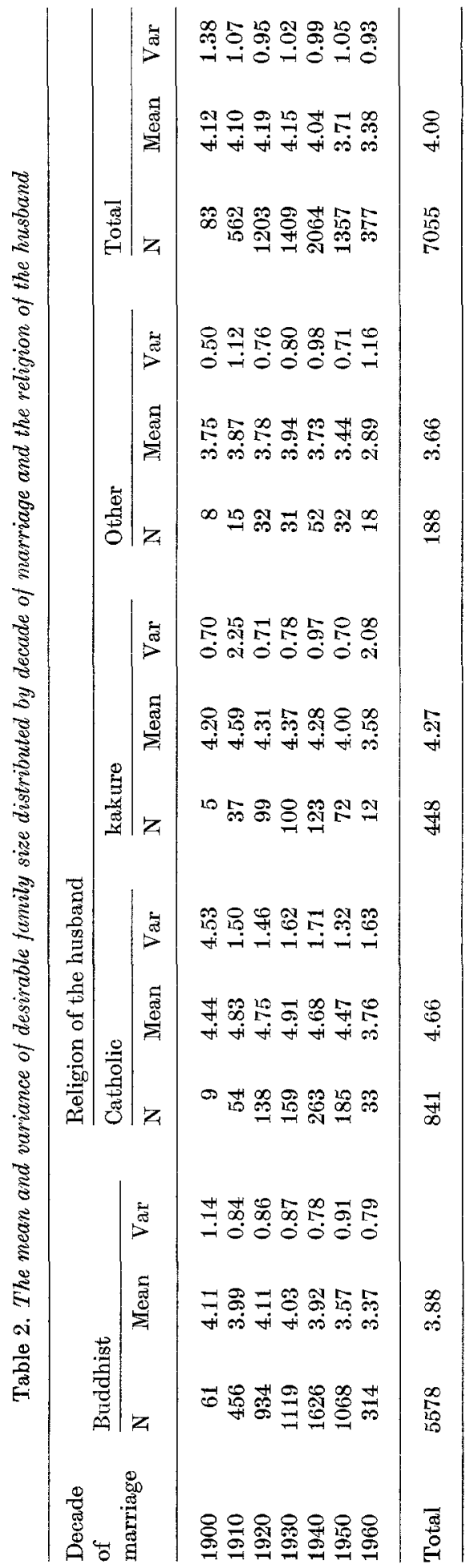


It is tempting to speculate that the figures just cited merely reflect the actual reproductive performances of the various families, and that each couple has, in a sense, merely articulated its own conduct. This can be no more than partially true, if true at all, for the correlation between the actual number of children born to a given family and the number of children stated to be desirable by that family (for families of completed reproduction) is low, albeit significantly different from zero $(r=0.19)$. A second line of evidence which makes this speculation improbable stems from the variances in number of children desirable observed in almost all decades; these variances are very much smaller than the variances in actual family sizes which are generally larger than the means. Moreover, the variances in number of children desirable are not conspicuously a function of date of marriage which is not true of actual family sizes. Finally, only 5 of the 7,055 families recorded in Table 2 thought that no children were desirable; whereas a much larger number are, in fact, childless. This uniformity of response would be expected if the individual respondent was simply repeating a culturally imposed norm.

Table 3 (see also Table 3 a) summarizes several analyses of the relationship of consanguinity and inbreeding to the desirable number of children, namely, an analysis based upon (1) all Buddhist, Catholic and kakure marriages (the "others" have been excluded) contracted in the years $1900-1964,(2)$ all such marriages contracted in the interval 1920-1939, and (3) all farm and non-farm marriages in the two previously stated intervals where sufficient information exists to form a socio-economic score. We note a significant effect of year of marriage in the years 1900-1964 among farm and non-farm marriages as well as among all marriages; number of children considered desirable increases as the number of years of marriage increases. This would be expected, of course, from Table 2 . In these same years, socio-economic status is significantly and inversely related to the number of offspring deemed desirable; as socio-economic standing increases the number of children viewed as desirable decreases. The effects of time and socio-economic standing are more pronounced in nonfarm than farm marriages. Although a few contrasts are significant, there is no consistent effect of either consanguinity or inbreeding, nor are there differences between the farm and non-farm communities in this regard.

When the data are restricted to the years 1920-1939, no significant effect of year of marriage emerges; socio-economic status continues to be inversely related to the number of children desirable, but significantly only among non-farm marriages. Again, the effects of consanguinity and inbreeding are inconsistent although significant in several instances. Among non-farm families relatively more children are desired when the wife is inbred than if she is not; among farm wives the effect is opposite in direction, but not significantly so. The difference between these values is significant, however, and no single, simple explanation other than chance can be advanced which will account for this finding. As Table 3 a reveals, the findings cited emerge also when the data are restricted to Buddhist households.

To recapitulate briefly, there is some evidence within these data that the attitudes toward reproduction, and more specifically family size may vary systematically with consanguinity and inbreeding; these differences are at most small, 
Table 3. An analysis of the relationship of number of children deemed desirable to length of cohabitation, socio-economic score, the coefficients of inbreeding of hasband and wite, $\mathrm{F}_{\mathrm{H}}$ and $\mathrm{F}_{\mathrm{W}}$, and consanguinity, the latter expressed as the coefficient of inbreeding of the issue arising from consanguineous marriages. Household heads only; all religions. Unless otherwise stated, the entries are regression coefficients with their standard errors

\begin{tabular}{llll}
\hline & All marriages & Nonfarm marriages & Farm marriages \\
\hline Years 1900-1964 & & \\
Number & 6601 & 2775 & 2009 \\
Mean & 4.09 & 4.14 & 4.25 \\
Years & $0.0135 \pm 0.0009^{\mathrm{b}}$ & $0.0186 \pm 0.0016^{\mathrm{b}}$ & $0.0046 \pm 0.0018^{\mathrm{a}}$ \\
SES & \multicolumn{2}{c}{$-0.0663 \pm 0.0055^{\mathrm{b}}$} & $-0.0242 \pm 0.0084^{\mathrm{a}}$ \\
$\mathrm{F}_{\mathrm{H}}(\%)$ & $0.0207 \pm 0.0088^{\mathrm{a}}$ & $0.0206 \pm 0.0158$ & $-0.0060 \pm 0.0129$ \\
$\mathrm{~F}_{\mathrm{W}}(\%)$ & $0.0101 \pm 0.0092$ & $0.0198 \pm 0.0140$ & $-0.0027 \pm 0.0153$ \\
$\mathrm{~F}_{\mathrm{I}}(\%)$ & $0.0187 \pm 0.0073^{\mathrm{a}}$ & $0.0077 \pm 0.0124$ & $0.0080 \pm 0.0108$ \\
Years $1920-1939$ & & \\
Number & 2478 & 879 & 889 \\
Mean & 4.16 & 4.15 & 4.27 \\
Years & $0.0021 \pm 0.0035$ & $-0.0011 \pm 0.0062$ & $0.0004 \pm 0.0060$ \\
SES & & $-0.0487 \pm 0.0087^{\mathrm{b}}$ & $-0.0155 \pm 0.0123$ \\
$\mathrm{~F}_{\mathrm{H}}(\%)$ & $-0.0086 \pm 0.0144$ & $0.0055 \pm 0.0286$ & $-0.0208 \pm 0.0188$ \\
FW(\%) & $0.0093 \pm 0.0160$ & $0.0653 \pm 0.0256^{\mathrm{b}}$ & $-0.0302 \pm 0.0249$ \\
$\mathrm{~F}_{\mathrm{I}}(\%)$ & $0.0248 \pm 0.0119^{\mathrm{a}}$ & $-0.0088 \pm 0.0224$ & $0.0320 \pm 0.0162$ \\
\hline
\end{tabular}

The mean is predicted for the year $1930, \mathrm{SES}=8$, and $\mathrm{F}_{\mathrm{H}}=\mathrm{F}_{\mathrm{W}}=\mathrm{F}_{\mathrm{I}}=0$.

a $p<0.05 ;{ }^{b} p<0.01$.

Table 3a. An analysis of the relationship of number of children deemed desirable to length of cohabitation, socio-economic score, the coefficients of inbreeding of husband and wite, $\mathrm{F}_{\mathrm{H}}$ and $\mathrm{F}_{\mathrm{W}}$, and consanguinity, the latter expressed as the coefficient of inbreeding of the issue arising from consanguineous marriages. Buddhist household heads only. The entries are regression coefficients with their standard errors unless otherwise stated

\begin{tabular}{|c|c|c|c|}
\hline & All marriages & Nonfarm marriages & Farm marriages \\
\hline \multicolumn{4}{|c|}{ Years 1900-1964 } \\
\hline Number & 5414 & 2504 & 1466 \\
\hline Mean & 3.97 & 4.06 & 4.08 \\
\hline Years & $0.0143 \pm 0.0010^{b}$ & $0.0192 \pm 0.0017 \mathrm{~b}$ & $0.0065 \pm 0.0020^{\mathrm{b}}$ \\
\hline SES & 二 & $-0.0553 \pm 0.0057 \mathrm{~b}$ & $-0.0114 \pm 0.0095$ \\
\hline $\mathrm{F}_{\Pi}(\%)$ & $0.0343 \pm 0.0096^{b}$ & $0.0184 \pm 0.0163$ & $0.0164 \pm 0.0147$ \\
\hline $\mathrm{F}_{\mathrm{W}}(\%)$ & $0.0245 \pm 0.0098^{b}$ & $0.0284 \pm 0.0145$ & $0.0207 \pm 0.0170$ \\
\hline $\mathrm{F}_{\mathrm{I}}(\%)$ & $0.0274 \pm 0.0079^{\mathrm{b}}$ & $0.0214 \pm 0.0128$ & $0.0159 \pm 0.0124$ \\
\hline \multicolumn{4}{|c|}{ Years 1920 - 1939} \\
\hline Number & 2019 & 805 & 655 \\
\hline Mean & 4.04 & 4.07 & 4.15 \\
\hline Years & $0.0043 \pm 0.0039$ & $0.0067 \pm 0.0065$ & $-0.0020 \pm 0.0070$ \\
\hline SES & - & $-0.0368 \pm 0.0090^{b}$ & $-0.0133 \pm 0.0140$ \\
\hline $\mathrm{E}_{\mathbf{H}}(\%)$ & $0.0055 \pm 0.0159$ & $0.0118 \pm 0.0292$ & $-0.0090 \perp 0.0218$ \\
\hline $\mathrm{F}_{\mathrm{W}}(\%)$ & $0.0299 \pm 0.0175$ & $0.0771 \pm 0.0267 \mathrm{~b}$ & $-0.0128 \pm 0.0290$ \\
\hline $\mathrm{F}_{\mathrm{I}}(\%)$ & $0.0272 \pm 0.0132^{\mathrm{a}}$ & $-0.0014 \pm 0.0227$ & $0.0326 \pm 0.0189$ \\
\hline
\end{tabular}

The mean is predicted for the year 1930, $\mathrm{SES}=8$, and $\mathrm{F}_{\mathrm{H}}=\mathrm{F}_{\mathrm{W}}=\mathrm{F}_{\mathrm{I}}=0$.

${ }^{\mathrm{a}} p<0.05 ;{ }^{\mathrm{b}} p<0.01$. 
but in the direction of favoring somewhat larger families as consanguinity and inbreeding increase. The most consistent and striking effect is, however, the dependence of desirable family size upon socio-economic level among non-farm marriages.

\section{Consanguinity and the Frequency of Childless Couples}

Stern and Charles (1945), in connection with maternal-fetal incompatibility with respect to the $\mathrm{Rh}$ system, were the first to point out that the probability of maternal-fetal incompatibility diminishes with inbreeding. To the extent, then, that childlessness may reflect maternal-fetal incompatibility, childless couples should diminish in frequency with increasing relationship of husband to wife if other factors are equal. Data on this issue are surprisingly sparse both in Japan and elsewhere. Among the few studies in Japan are those of Tanaka et al. (1964), and of Schull et al. (1962). The latter study found childless marriages to be more infrequent when the spouses were related than when they were not but the difference was not statistically significant; whereas Tanaka et al. (1964) report a significant, negative association of relationship of husband to wife to the frequency of infertile marriages, and a positive effect of inbreeding of the wife. We defer a discussion of these data until the results of the present study have been presented.

Attention here will be restricted to marriages contracted in the years 19201939 ; thus, a minimum of 25 years of cohabitation will have obtained for each couple. As earlier stated, the data stem from interviews collated, where possible with governmental records. Childless marriages are defined in this context as those marriages stated by husband, wife, or both to have produced no issue and where this statement was not contradicted by the koseki. It should be borne in mind, however, that fetal deaths and occasionally a liveborn infant succumbing in the first several days of life are not recorded in the koseki. Thus, some "childless" marriages may have produced a child which no longer survives, and whose very birth the parents did not recall at the census. Whatever bias this might introduce would presumably increase the apparent frequency of childlessness among consanguineous marriages since their children are at a greater risk of death (Schull et al., 1970).

Table 4 sets forth the results of several analyses. One relates childlessness to year of marriage, inbreeding and consanguinity. A second exposes the role of socio-economic status, inbreeding and consanguinity to childlessness. Finally, the third presents the effect of inbreeding and consanguinity on childlessness when year of marriage and socio-economic status are ignored. Within these two decades childlessness does not vary significantly with year of marriage; in point of fact, even the face value dependence is a trivial one. As a consequence year of marriage has been ignored in the analysis of the role of socio-economic factors. The latter, however, also appear to exert little if any influence on the frequency of childless marriages within the farm and non-farm communities. Finally, contrary to the observations of Tanaka et al. (1964), there is no discernible significant effect of inbreeding of husband and wife upon the frequency of childlessness. However, consanguinity of husband and wife does significantly alter the frequency of childlessness in the two analyses based upon the larger numbers of observations. 
Table 4. An analysis of the effects of length of cohabitation, socio-economic status, and consanguinity and inbreeding on the frequency of childless marriages. The data are limited to marriages contracted in the years 1920 through 1939. The entries are regression coefficients with their standard errors unless otherwise stated

\begin{tabular}{|c|c|c|}
\hline & All marriages & Buddhist marriages \\
\hline \multirow{7}{*}{$\begin{array}{l}\text { Number } \\
\text { Mean } \\
\text { Years } \\
\text { FH }(\%) \\
\text { FW }_{W}(\%) \\
\text { FI }_{\mathbf{I}}(\%)\end{array}$} & 3031 & 2478 \\
\hline & 0.0940 & 0.0982 \\
\hline & $0.0001 \pm 0.0010$ & $0.0000 \pm 0.0011$ \\
\hline & $-0.5559 \pm 0.4363$ & $-0.5161 \pm 0.5076$ \\
\hline & $-0.3575 \pm 0.5213$ & $-0.5303 \pm 0.5683$ \\
\hline & $-0.9228 \pm 0.3066^{\mathrm{a}}$ & $-0.9077 \pm 0.3439 \mathrm{a}$ \\
\hline & Nonfarm marriages & $\$$ Farm marriages \\
\hline \multirow{7}{*}{$\begin{array}{l}\text { Number } \\
\text { Mean } \\
\text { SES } \\
\text { FH }_{1}(\%) \\
\text { FW }_{W}(\%) \\
F_{X}(\%)\end{array}$} & 1011 & 923 \\
\hline & 0.0698 & 0.0703 \\
\hline & $-0.0015 \pm 0.0023$ & $-0.0033 \pm 0.0037$ \\
\hline & $-0.0224 \pm 1.0738$ & $-0.0837 \pm 0.6690$ \\
\hline & $0.2333 \pm 0.9124$ & $-0.3668 \pm 0.9615$ \\
\hline & $-0.5045 \pm 0.5978$ & $-0.6898 \pm 0.5032$ \\
\hline & All marriages & Buddhist marriages \\
\hline Number & 3031 & 2478 \\
\hline Mean & 0.1031 & 0.0956 \\
\hline $\mathrm{F}_{\mathrm{H}}(\%)$ & $-0.2024 \pm 0.4598$ & $-0.2328 \pm 0.3924$ \\
\hline $\mathrm{F}_{\mathrm{W}}(\%)$ & $-0.6247 \pm 0.4762$ & $-0.7062 \pm 0.4169$ \\
\hline$F_{\mathbf{I}}(\%)$ & $-0.7650 \pm 0.3231^{\mathrm{a}}$ & $-0.7965 \pm 0.2763^{\mathrm{a}}$ \\
\hline
\end{tabular}

The mean is predicted, where relevant, for the year $1930, \mathrm{SES}=8$, and $\mathrm{F}_{\mathrm{H}}=\mathrm{F}_{\mathrm{W}}=\mathrm{F}_{\mathrm{I}}=0$. a $p<0.01$.

This observation agrees with the findings of Tanaka et al. (1964) and those of Schull et al. (1962) previously cited. On the basis of the present data, a first cousin marriage has approximately one chance in 20 of being without children whereas there is 1 chance in 10 that unrelated spouses will be childless. For this reason if no other, one might expect the consanguineous marriage to be relatively more fertile than the non-consanguineous marriage, on the average. We shall shortly attempt to estimate the contribution of this phenomenon to differential fertility among consanguinity classes.

\section{Fertility and the Consanguineous Marriage}

The decline in pre-reproductive mortality which has occurred and continues to occur in developed and developing nations emphasizes anew the possible role of differential fertility without concomitant differential mortality in the maintenance of genetic polymorphisms. But absolute fertility is itself on the decline in many nations, and the differential associated with one phenotype as contrasted with another, though relatively unchanged, may become more difficult to demonstrate because it is smaller absolutely. The time to measure such differentials, if they exist, is now. As previously stated, fertility is influenced by many factors, 
Table 5. An analysis of the relationship of total pregnancies to length of cohabitation, socio-economic score, the coefficient of inbreeding of husband and wite, $\mathrm{F}_{\mathrm{H}}$ and $\mathrm{F}_{\mathrm{W}}$, and of their issue, $\mathrm{F}_{\mathbf{I}}$. All religions. Unless stated otherwise, the entries are regression coefficients with their standard errors

\begin{tabular}{|c|c|c|c|}
\hline & All marriages & Nonfarm marriages & Farm marriages \\
\hline \multicolumn{4}{|c|}{ Years $1900-1964$} \\
\hline Number & 9618 & 3761 & 2099 \\
\hline Mean & 5.34 & 5.44 & 6.03 \\
\hline Years & $0.2049 \pm 0.0025^{b}$ & $0.2035 \pm 0.0042^{\mathrm{b}}$ & $0.2590 \pm 0.0077$ \\
\hline Years ${ }^{2}$ & $-0.0021+0.0004^{b}$ & $-0.0020+0.0001 \mathrm{~b}$ & $-0.0029+0.0001 b$ \\
\hline SES & 二- & $-0.1386 \pm 0.0169 \mathrm{~b}$ & $-0.1503 \pm 0.0383 b$ \\
\hline $\mathrm{ES}^{2}$ & - & $0.0014 \pm 0.0007^{\mathrm{a}}$ & $0.0053 \pm 0.0020^{b}$ \\
\hline$F_{H}(\%)$ & $0.0207 \pm 0.0074^{b}$ & $0.0406 \pm 0.0131^{\mathrm{b}}$ & $-0.0373 \pm 0.0128^{b}$ \\
\hline $\mathrm{F}_{\mathrm{W}}(\%)$ & $0.0190 \pm 0.0077^{\mathrm{a}}$ & $0.0371 \pm 0.0122^{\mathrm{b}}$ & $-0.0163 \pm 0.0151$ \\
\hline $\mathrm{F}_{\mathrm{I}}(\%)$ & $0.0589 \pm 0.0059 \mathrm{~b}$ & $0.0401 \pm 0.0103^{b}$ & $0.0559 \pm 0.0106^{\mathrm{b}}$ \\
\hline \multicolumn{4}{|c|}{ Years $1920-1939$} \\
\hline Number & 3031 & 1013 & 923 \\
\hline Mean & 5.12 & 5.15 & 5.90 \\
\hline Years & $0.1378 \pm 0.0361^{b}$ & $-0.0425 \pm 0.0733$ & $0.2496 \pm 0.0782$ \\
\hline Years $^{2}$ & $-0.0007 \pm 0.0005$ & $0.0018 \pm 0.0010$ & $-0.0024 \pm 0.0011^{a}$ \\
\hline SES & - & $-0.1867 \pm 0.0233^{b}$ & $0.0818 \pm 0.0582$ \\
\hline $\mathrm{SES}^{2}$ & - & $0.0024 \pm 0.0009^{b}$ & $-0.0060 \pm 0.0030^{\mathrm{a}}$ \\
\hline $\mathrm{F}_{\mathrm{H}}(\%)$ & $0.0606 \pm 0.0134^{b}$ & $0.1057 \pm 0.0269^{b}$ & $-0.0339 \pm 0.0186$ \\
\hline $\mathrm{F}_{\mathrm{W}}(\%)$ & $0.0329 \pm 0.0144^{a}$ & $0.0712 \pm 0.0248^{b}$ & $0.0066 \pm 0.0248$ \\
\hline $\mathrm{F}_{\mathrm{I}}(\%)$ & $0.0891 \pm 0.0105^{b}$ & $0.0572 \pm 0.0207^{\mathrm{b}}$ & $0.1016 \pm 0.0160^{b}$ \\
\hline
\end{tabular}

The mean is predicted for the year 1930, $\mathrm{SES}=8$, and $\mathbf{F}_{\mathbf{H}}=\mathrm{F}_{\mathrm{W}}=\mathrm{F}_{\mathbf{I}}=0$. ${ }^{\mathrm{a}} p<0.05 ;{ }^{\mathrm{b}} p<0.01$.

the adequate control of which is both formidable and challenging; however, intuitively one presumes this control would be best effected in those instances where the initial variability in these concomitants was small. Arguments have been presented here and in previous papers (see Schull et al., 1968, 1970) why this would seem to be true for Hirado. Even here, however, some further effort to delineate and remove extraneous sources of variation was obviously indicated. Of these, three seemed especially important, namely, length of cohabitation, urban-rural differentials as reflected in farm and non-farm occupations, and socioeconomic status.

Before the data are examined it seems advisable to reiterate the results predicted if reproductive compensation is, in fact, occurring. First, we anticipate both a greater number of pregnancies and a greater number of livebirths in the consanguineous as contrasted with the non-consanguineous marriage. Second, "net fertility", here defined as the number of livebirths minus the number of prereproductive deaths, that is, the number of liveborn infants surviving to adulthood, should differ little, if at all, as a function of consanguinity. Tables 5 and 5 a exhibit several analyses of the association of total number of pregnancies with length of cohabitation in years, socio-economic status, inbreeding and the relationship of husband to wife. These various analyses are overlapping, of course, but within a given time period, the analyses of farm and non-farm families are independent. The remarks to follow are addressed primarily to the period 1920-1939; attention 
Table 5a. An analysis of the relationship of total pregnancies to length of cohabitation, socioeconomic score, the coefficients of inbreeding of husband and wife, $\mathrm{F}_{\mathrm{H}}$ and $\mathrm{F}_{\mathrm{W}}$, and of their issue, $\mathrm{F}_{\mathrm{I}}$. The data are restricted to Buddhist households. The entries are regression coefficients with their standard errors unless otherwise stated

\begin{tabular}{|c|c|c|c|}
\hline & All marriages & Nonfarm marriages & Farm marriages \\
\hline \multicolumn{4}{|c|}{ Years $1900-1964$} \\
\hline Number & 7813 & 3384 & 1503 \\
\hline Mean & 5.08 & 5.34 & 5.74 \\
\hline Year & $0.1926 \pm 0.0027^{b}$ & $0.1918 \pm 0.0044^{b}$ & $0.2391 \pm 0.0090^{\mathrm{b}}$ \\
\hline Year $^{2}$ & $-0.0019 \pm 0.0001^{b}$ & $-0.0018 \pm 0.0001^{\mathrm{a}}$ & $-0.0025 \pm 0.0002^{b}$ \\
\hline SES & - & $-0.1072 \pm 0.0174 \mathrm{~b}$ & $-0.1180 \pm 0.0438 \mathrm{~b}$ \\
\hline SES $^{2}$ & - & $0.0006 \pm 0.0007$ & $0.0037 \pm 0.0022$ \\
\hline $\mathrm{F}_{\mathrm{H}}(\%)$ & $0.0344 \pm 0.0081^{b}$ & $0.0455 \pm 0.0137^{b}$ & $-0.0363 \pm 0.0145^{a}$ \\
\hline$F_{W}(\%)$ & $0.0289 \pm 0.0083^{b}$ & $0.0432 \pm 0.0126^{b}$ & $-0.0126 \pm 0.0169$ \\
\hline $\mathrm{F}_{\mathrm{I}}(\%)$ & $0.0849 \pm 0.0064^{b}$ & $0.0581 \pm 0.0107^{b}$ & $0.1027 \pm 0.0122^{b}$ \\
\hline \multicolumn{4}{|c|}{ Years $1920-1939$} \\
\hline Number & 2478 & 932 & 670 \\
\hline Mean & 4.91 & 5.06 & 5.69 \\
\hline Year & $0.1539 \pm 0.0416^{b}$ & $-0.0014 \pm 0.0767$ & $0.3172 \pm 0.0941^{b}$ \\
\hline Year $^{2}$ & $-0.0009 \pm 0.0006$ & $0.0013 \pm 0.0011$ & $-0.0031 \pm 0.0013^{\mathrm{a}}$ \\
\hline SES & 一 & $-0.1411 \pm 0.0240^{b}$ & $0.0607 \pm 0.0663$ \\
\hline SES $^{2}$ & - & $0.0013 \pm 0.0009$ & $-0.0054 \pm 0.0033$ \\
\hline $\mathrm{F}_{\mathrm{H}}(\%)$ & $0.0636 \pm 0.0148^{b}$ & $0.1121 \pm 0.0274^{b}$ & $-0.0684 \pm 0.0215 \mathrm{~b}$ \\
\hline $\mathrm{FW}(\%)$ & $0.0526 \pm 0.0158^{b}$ & $0.0766 \pm 0.0258^{b}$ & $0.0016 \pm 0.0290$ \\
\hline$F_{\mathbf{I}}(\%)$ & $0.1121 \pm 0.0115^{b}$ & $0.0738 \pm 0.0210^{b}$ & $0.1490 \pm 0.0186^{b}$ \\
\hline
\end{tabular}

The mean is predicted for the year 1930, $\mathrm{SES}=8$, and $\mathrm{F}_{\mathrm{H}}=\mathrm{F}_{\mathrm{W}}=\mathrm{F}_{\mathrm{I}}=0$. ${ }^{\mathrm{a}} p<0.05 ;{ }^{\mathrm{b}} p<0.01$.

will be directed to the interval 1900-1964 only when a discrepancy exists between an analysis of these data and the former.

Number of pregnancies is positively and significantly related to years of marriage (Table 5). In the years 1900-1964 this is not unexpected since the more recent marriages obviously have not completed their reproduction, but another explanation must be sought for the association observed in the $1920-1939$ marriages. The most recent of these was contracted more than 24 years prior to the census, and thus most, if not all spouses would have completed their reproduction before their families were enumerated. It seems more likely, therefore, that the dependency of number of pregnancies upon years of marriage in this instance reflects the known decline in mean number of births since the turn of the century. Taeuber (1958) reports an approximately $20 \%$ reduction in birth rate in the years 1920 to 1940 ; in 1920 there were 77 female births per 1,000 women, 70 in 1930, and 61 in 1940. This downward trend continued into the mid-fifties, but since then the rates have been more-or-less stable. It may be argued, considering the figures just cited, that it is unrealistic to assume that all of the effect of years of cohabitation upon total pregnancies can be removed by a linear term. Indeed, when a quadratic term in time is added to the model it removes a significant amount of variability in all comparisons involving the 1900-1964 data, but not routinely in the 1920-1939 observations. 
Table 6. An analysis of the relationship of total livebirths to length of cohabitation, socio-economic score, the coefficients of inbreeding of husband and wite, $\mathrm{F}_{\mathbf{H}}$ and $\mathrm{F}_{\mathrm{W}}$, and of their issue, $\mathrm{F}_{\mathrm{I}}$. All religions. Unless stated otherwise, the entries are regression coefficients with their standard errors

\begin{tabular}{|c|c|c|c|}
\hline & All marriages & Nonfarm marriages & Farm marriages \\
\hline \multicolumn{4}{|c|}{ Years $1900-1964$} \\
\hline Number & 9618 & 3761 & 2099 \\
\hline Mean & 5.10 & 5.14 & 5.76 \\
\hline Year & $0.1988 \pm 0.0025^{b}$ & $0.1865 \pm 0.0042^{b}$ & $0.2423 \pm 0.0077$ \\
\hline Year $^{2}$ & $-0.0019 \pm 0.0000^{b}$ & $-0.0016 \pm 0.0000^{b}$ & $-0.0025 \pm 0.0001 \mathrm{~b}$ \\
\hline SES & 二 & $-0.1854 \pm 0.0169 \mathrm{~b}$ & $-0.1854 \pm 0.0383^{b}$ \\
\hline $\mathrm{SES}^{2}$ & $\ldots$ & $0.0030 \pm 0.0007^{b}$ & $0.0069 \pm 0.0020^{\mathrm{b}}$ \\
\hline$F_{H}(\%)$ & $0.0260 \pm 0.0074^{b}$ & $0.0437 \pm 0.0131^{b}$ & $-0.0331 \pm 0.0128^{b}$ \\
\hline $\mathrm{F}_{\mathrm{W}}(\%)$ & $0.0205 \pm 0.0077 \mathrm{~b}$ & $0.0380 \pm 0.0103^{\mathrm{b}}$ & $-0.0052 \pm 0.0151$ \\
\hline $\mathrm{F}_{\mathrm{I}}(\%)$ & $0.0518 \doteq 0.0059 b$ & $0.0302 \pm 0.0103^{b}$ & $0.0441 \pm 0.0106^{\mathrm{b}}$ \\
\hline \multicolumn{4}{|c|}{ Years $1920-1939$} \\
\hline Number & 3031 & 1013 & 923 \\
\hline Mean & $\mathbf{5 . 0 0}$ & 5.01 & 5.73 \\
\hline Year & $0.1826 \pm 0.0361^{b}$ & $0.0312 \pm 0.0733$ & $0.3382 \pm 0.0782^{\mathrm{b}}$ \\
\hline Year $^{2}$ & $-0.0013 \pm 0.0005^{b}$ & $0.0010 \pm 0.0010$ & $-0.0034 \pm 0.0011^{b}$ \\
\hline SES & - & $-0.2019 \pm 0.0233^{\mathrm{b}}$ & $0.0267 \pm 0.0582$ \\
\hline $\mathrm{SES}^{2}$ & - & $0.0029 \pm 0.0009 \mathrm{~b}$ & $-0.0040 \pm 0.0030$ \\
\hline $\mathrm{F}_{\mathrm{H}}(\%)$ & $0.0437 \pm 0.0134^{b}$ & $0.1108 \pm 0.0269^{b}$ & $-0.0507 \pm 0.0186^{b}$ \\
\hline $\mathrm{FW}_{\mathrm{W}}(\%)$ & $0.0375 \pm 0.0144^{b}$ & $0.0725 \pm 0.0248^{b}$ & $0.0266 \pm 0.0248$ \\
\hline$F_{I}(\%)$ & $0.0747 \pm 0.0105^{b}$ & $0.0415 \pm 0.0207^{\mathrm{a}}$ & $0.0853 \pm 0.0160^{b}$ \\
\hline
\end{tabular}

The mean is predicted for the year 1930, $\mathrm{SES}=8$, and $\mathrm{F}_{\mathrm{H}}=\mathrm{F}_{\mathrm{W}}=\mathrm{F}_{\mathrm{I}}=0$.

${ }^{\mathrm{a}} p<0.05 ;{ }^{\mathrm{b}} p<0.01$.

Socio-economic status is inversely related to the number of pregnancies in the 1900-1964 data; that is to say, the number of pregnancies increases as socioeconomic status decreases. This is a fairly commonly reported phenomenon. Of greater interest here is the difference in degree of the effects of time and socioeconomic status among farm and non-farm families in the 1920-1939 observations, a difference which is highly significant. The roles of time and socioeconomic status appear reversed; time is the greater contributor to variability in total pregnancies among farm families whereas socio-economic status is among non-farm marriages. Presumably this is ascribable to the greater variability in SES in the latter instance than in the former, and the correlation between time and socio-economic status which exists in these data, i. e., the older marriages are, in general, economically better off.

Inbreeding and consanguinity exert a significant effect upon reproductive performance on this island. Relationship of husband to wife is positively associated with increasing numbers of pregnancies, and consistent in all of the analyses. Moreover, there is no significant difference between farm and non-farm families. Inbreeding of husband and wife present a somewhat more complicated picture. While both increase the number of pregnancies in the non-farm families, they do not exert a significant effect in the farm group. Both with respect to husband's inbreeding and wife's inbreeding, the difference between regression coefficients for farm and non-farm families is a significant one. Note also that in 
Table $6 \mathrm{a}$. An analysis of the relationship of total livebirths to length of cohabitation, socio-economic score, the coefficient of inbreeding of husband and wife, $\mathrm{F}_{\mathrm{H}}$ and $\mathrm{F}_{\mathrm{W}}$, and of their issue, $\mathrm{F}_{\mathrm{I}}$. The data are restricted to Buddhist households. The entries are regression coefficients with their standard errors unless otherwise stated

\begin{tabular}{|c|c|c|c|}
\hline & All marriages & Nonfarm marriages & Farm marriages \\
\hline \multicolumn{4}{|c|}{ Years $1900-1964$} \\
\hline Number & 7813 & 3384 & 1503 \\
\hline Mean & 4.86 & 4.97 & 5.55 \\
\hline Year & $0.1844 \pm 0.0062^{b}$ & $0.1727 \pm 0.0044^{b}$ & $0.2229 \pm 0.0090$ \\
\hline Year $^{2}$ & $-0.0016 \pm 0.0002^{b}$ & $-0.0013 \pm 0.0001^{b}$ & $-0.0021 \pm 0.0002$ \\
\hline SES & 二 & $-0.3813+0.0459 \mathrm{~b}$ & $0.8119+0.1468$ \\
\hline $\mathrm{SES}^{2}$ & - & $0.0183 \pm 0.0031^{b}$ & $-0.0934 \pm 0.0148$ \\
\hline $\mathrm{F}_{\mathrm{H}}(\%)$ & $0.0456 \pm 0.0081^{b}$ & $0.0507 \pm 0.0137^{b}$ & $-0.0219 \pm 0.0145$ \\
\hline $\mathrm{FW}(\%)$ & $0.0332 \pm 0.0083^{b}$ & $0.0451 \pm 0.0126^{b}$ & $0.0044 \pm 0.0169$ \\
\hline $\mathrm{F}_{\mathrm{I}}(\%)$ & $0.0791 \pm 0.0064^{b}$ & $0.0490 \pm 0.0107^{b}$ & $0.0986 \pm 0.0122$ \\
\hline \multicolumn{4}{|c|}{ Years $1920-1939$} \\
\hline Number & 2478 & 932 & 670 \\
\hline Mean & 4.98 & 4.92 & 5.51 \\
\hline Year & $0.0821 \pm 0.0631$ & $0.0733 \pm 0.0767$ & $0.4423 \pm 0.0941^{b}$ \\
\hline Year $^{2}$ & $0.0031 \pm 0.0018$ & $0.0004 \pm 0.0011$ & $-0.0047 \pm 0.0013$ \\
\hline SES & - & $-0.1560 \pm 0.0240^{b}$ & $0.0033 \pm 0.0663$ \\
\hline $\mathrm{SES}^{2}$ & - & $0.0018 \pm 0.0009^{\mathrm{a}}$ & $-0.0029 \pm 0.0033$ \\
\hline $\mathrm{F}_{\mathrm{H}}(\%)$ & $0.0555 \pm 0.0148^{b}$ & $0.1156 \pm 0.0274^{b}$ & $-0.0759 \pm 0.0215$ \\
\hline $\mathrm{Fw}(\%)$ & $0.0609 \pm 0.0158^{b}$ & $0.0790 \pm 0.0258^{b}$ & $0.0276 \pm 0.0290$ \\
\hline $\mathrm{Fr}_{\mathrm{I}}(\%)$ & $0.1011 \pm 0.0115^{b}$ & $0.0587+0.0210^{\mathrm{b}}$ & $0.1365 \pm 0.0186^{\mathrm{b}}$ \\
\hline
\end{tabular}

The mean is predicted for the year 1930, $\mathrm{SES}=8$, and $\mathrm{F}_{\mathrm{H}}=\mathrm{F}_{\mathrm{W}}=\mathrm{F}_{\mathrm{I}}=0$.

${ }^{\mathrm{a}} p<0.05 ;{ }^{\mathrm{b}} p<0.01$.

the 1900-1964 data the effect of husband's inbreeding is itself significantly different from zero contrary to the situation in the 1920-1939 data. The origins of this difference between farm and non-farm marriages, if real, are not clear; some may reflect the dissimilar motivations to consanguineous marriages among farm and non-farm folk. The Buddhists alone (see Table 5a) differ little from all religious groups collectively save, perhaps, in the effect of consanguinity itself which seems larger particularly among farm families. This undoubtedly is attributable to the removal of the Catholics most of whom are farmers, contribute disproportionately to the non-related, non-inbred group, and have, on the average, larger families than the Buddhists and kakure.

Analyses of the relationship of inbreeding and consanguinity to total livebirths are tabulated in Tables 6 and 6 a. Table 6 presents an analysis in which linear and quadratic components are estimated for length of cohabitation and SES. With a single exception these two variables exert a relatively large and significant effect upon the total number of livebirths which characterizes a particular mating. It seemed desirable under these circumstances to extract as much variability assignable to these concomitants as possible since conceivably some of this variation might otherwise be erroneously attributed to inbreeding and consanguinity. Both the linear and quadratic terms are significant in most instances; parenthetically, cubic expressions did not, in general, remove significantly more variability. 
Table 7. An analysis of the relationship of total livebirths to length of cohabitation, socio-economic score, the coefficient of inbreeding of husband and wife, $\mathrm{F}_{\mathrm{H}}$ and $\mathrm{F}_{\mathrm{W}}$, and of their issue, $\mathrm{F}_{\mathrm{I}}$. Only those marriages are included which have produced at least one liveborn child. All religions. Unless otherwise stated, the entries are regression coefficients with their standard errors

\begin{tabular}{|c|c|c|c|}
\hline & All marriages & Nonfarm marriages & Farm marriages \\
\hline \multicolumn{4}{|c|}{ Years $1900-1964$} \\
\hline Number & 8546 & 3331 & 1949 \\
\hline Mean & 5.65 & 5.62 & 6.19 \\
\hline Year & $0.2117+0.0027 b$ & $0.1903+0.0047^{b}$ & $0.2537+0.0082^{b}$ \\
\hline Year $^{2}$ & $-0.0019 \pm 0.0000^{b}$ & $-0.0015=0.0001^{\mathrm{b}}$ & $-0.0025 \pm 0.0001^{b}$ \\
\hline SES & - & $-0.1813 \pm 0.0174^{\mathrm{b}}$ & $-0.1995 \pm 0.0395^{b}$ \\
\hline SES $^{2}$ & _- & $0.0028+0.0007 \mathrm{~b}$ & $0.0075+0.0020^{b}$ \\
\hline $\mathrm{F}_{\mathrm{H}}(\%)$ & $0.0253 \pm 0.0078^{b}$ & $0.0430+0.0140^{\mathrm{b}}$ & $-0.0282 \pm 0.0133^{\mathrm{a}}$ \\
\hline $\mathrm{Fw}(\%)$ & $0.0035 \pm 0.0081$ & $0.0279 \pm 0.0128^{a}$ & $-0.0266 \pm 0.0155$ \\
\hline$F_{I}(\%)$ & $0.0419 \pm 0.0062^{b}$ & $0.0222 \pm 0.0108^{\mathrm{a}}$ & $0.0222 \pm 0.0109^{\mathrm{a}}$ \\
\hline \multicolumn{4}{|c|}{ Years $1920-1939$} \\
\hline Number & 2726 & 921 & 849 \\
\hline Mean & 5.56 & 5.50 & 6.09 \\
\hline Year & $0.1654 \pm 0.0395^{b}$ & $0.0466 \pm 0.0769$ & $0.0132 \pm 0.0673$ \\
\hline Year $^{2}$ & $-0.0009 \pm 0.0006$ & $0.0007 \pm 0.0011$ & $0.0018 \pm 0.0011$ \\
\hline SES & \pm & $-0.1768 \pm 0.0239^{b}$ & $-0.3506 \pm 0.0625^{b}$ \\
\hline SES $^{2}$ & - & $0.0020 \pm 0.0009^{\mathrm{a}}$ & $0.0126 \pm 0.0032^{b}$ \\
\hline $\mathrm{F}_{\mathrm{H}}(\%)$ & $0.0514 \pm 0.0142^{b}$ & $0.1081 \pm 0.0281^{\mathrm{b}}$ & $-0.0072 \pm 0.0185$ \\
\hline $\mathrm{F}_{W}(\%)$ & $0.0283 \pm 0.0151$ & $0.0719 \pm 0.0260^{\mathrm{b}}$ & $-0.0364 \pm 0.0225$ \\
\hline$F_{I}(\%)$ & $0.0470 \pm 0.0110 \mathrm{~b}$ & $0.0456 \pm 0.0219 a$ & $0.0368 \pm 0.0159^{a}$ \\
\hline
\end{tabular}

The mean is predicted for the year 1930, $\mathrm{SES}=8$, and $\mathrm{F}_{\mathrm{H}}=\mathrm{F}_{\mathrm{W}}=\mathrm{F}_{\mathrm{I}}=0$. a $p<0.05 ;{ }^{b} p<0.01$.

Interestingly, the addition of quadratic expressions in time and SES does not alter appreciably the estimates of the effects of inbreeding and consanguinity from those obtaining when only linear terms are employed, which suggests that the effects of consanguinity and inbreeding are largely independent of those of time and SES.

There remains religion to consider before the effects of inbreeding and consanguinity are examined more closely. In Table 6 a are the results of an analysis which restricts the data to the Buddhist community. One difference between this analysis and that in Table 6 is noteworthy; the regression coefficients associated with consanguinity and inbreeding are larger presumably for the same reasons cited with respect to total pregnancies. But, in the main, the effects observed in the three religious groups collectively emerge as clearly among the Buddhists alone. As for total pregnancies, there are some ambiguities; thus the effect of consanguinity is similar in farm and non-farm groups, but not the effects of inbreeding. Paternal inbreeding affects the number of liveborn children significantly in both occupational groups, but in a dissimilar fashion; moreover, this difference is a significant one. The effects of maternal inbreeding are the same in the farm and non-farm families at least insofar as sign is concerned, but the sizes of the regression coefficients are markedly different. Again, the consanguinity 
effect is appreciably larger in farm than in non-farm families among Buddhists, but not when religious affiliation is ignored.

Before the findings just described are enlarged upon, it seems appropriate to examine the effect of consanguinity and inbreeding upon the number of livebirths after allowance for the effect of consanguinity and inbreeding upon the frequency of childlessness previously reported. Table 7 sets out an analysis based upon only those families with one or more liveborn children. Childless spouses as well as those spouses who have produced only stillborn infants or infants dying in utero have been excluded. This may seem an overly restrictive approach; two observations are pertinent to this point of view. First, we have been unable to demonstrate a significant increase or decrease in the frequency of stillbirths with either consanguinity or inbreeding in these data; hence exclusion of families with only stillborn infants or fetal deaths does not prejudice the analysis with respect to consanguinity and inbreeding presumably. Second, most geneticists would surmise, on prior grounds, that if consanguinity or inbreeding affected the occurrence of fetal deaths or stillbirths at all, they would increase the frequency. If this were true, exclusion of fetal deaths and stillbirths under the circumstances described would overcorrect for the effects of inbreeding and consanguinity on the frequency of childlessness. Removal of the families stated diminishes the effect of consanguinity somewhat, but significance still obtains in both the farm and non-farm groups. However, the effect of this removal is somewhat larger in the farm group than in the non-farm group as judged by the actual sizes of the regression coefficients themselves. Viewed in terms of the regression coefficients associated with the consanguinity effect, exclusion of those families with no liveborn infants diminishes the effect of the relationship of the spouses from 0.0853 to 0.0368 in farm families but produces an inappreciable effect upon non-farm families.

It would seem clear from the data presented thus far that on Hirado the total number of pregnancies of a couple as well as the number of liveborn children increases systematically and significantly with biological relationship on the part of the spouses. There also exists a well-established norm of reproduction which varies somewhat with time but to a greater extent with socio-economic level. Neither consanguinity nor inbreeding are, however, consistently and significantly associated with the number of children deemed desirable. This norm presumably guides reproductive standards to some extent, for the number of children considered desirable and the number of children born to families with completed reproduction is significantly correlated. There remains to be established that the known higher mortality among the liveborn children of consanguineously married parents serves to level or at least reduce appreciably the observed fertility differences.

Tables 8 and 8 a present the results of analyses of the effects of length of cohabitation, socio-economic status, and consanguinity and inbreeding upon "net fertility." As earlier asserted, "net fertility" is merely the number of liveborn children of a family minus the number of children known to have died of nonaccidental causes prior to their twenty-first birthdays. Since not all of the children born to the various families in this study have been exposed to risk of death for 21 or more years, the actual "net fertility" of many families may ultimately prove lower than here recorded. Again, we emphasize the data from 1920-1939 
Table 8. An analysis of the relationship of "net fertility" to length of cohabitation, socio-economic score, the coefficient of inbreeding of husband and wife, $\mathrm{F}_{\mathrm{H}}$ and $\mathrm{F}_{\mathrm{W}}$, and of their issue, $\mathrm{F}_{\mathrm{I}}$. All religions. Unless otherwise stated, the entries are regression coefficients with their standard errors

\begin{tabular}{|c|c|c|c|}
\hline & All marriages & Nonfarm marriages & Farm marriages \\
\hline \multicolumn{4}{|c|}{ Years $1900-1964$} \\
\hline $\begin{array}{l}\text { Number } \\
\text { Mean } \\
\text { Year } \\
\text { Year' } \\
\text { SES } \\
\text { SES }^{2} \\
\text { FH }_{\mathbf{H}}(\%) \\
\mathrm{F}_{\mathrm{W}}(\%) \\
\mathrm{F}_{\mathbf{I}}(\%)\end{array}$ & $\begin{array}{l}9613 \\
4.32 \\
0.1656 \pm 0.0025^{\mathrm{b}} \\
-0.0017 \pm 0.0000^{\mathrm{b}} \\
- \\
- \\
0.0231 \pm 0.0074^{\mathrm{b}} \\
0.0174 \pm 0.0077^{\mathrm{a}} \\
0.0203 \pm 0.0059^{\mathrm{b}}\end{array}$ & $\begin{array}{l}3761 \\
4.39 \\
0.1729 \pm 0.0042^{\mathrm{b}} \\
-0.0019 \pm 0.0001^{\mathrm{b}} \\
-0.1410 \pm 0.0169^{\mathrm{b}} \\
0.0022 \pm 0.0007^{\mathrm{b}} \\
0.0462 \pm 0.0131^{\mathrm{b}} \\
0.0226 \pm 0.0122 \\
0.0125 \pm 0.0103\end{array}$ & $\begin{array}{l}2099 \\
4.85 \\
0.2002 \pm 0.0077 \\
-0.0022 \pm 0.0001 \\
-0.2250 \pm 0.0383 \\
0.0091 \pm 0.0020 \\
-0.0252 \pm 0.0128 \\
0.0013 \pm 0.0151 \\
0.0168 \pm 0.0106\end{array}$ \\
\hline \multicolumn{4}{|c|}{ Years $1920-1939$} \\
\hline $\begin{array}{l}\text { Number } \\
\text { Mean } \\
\text { Year } \\
\text { Year } \\
\text { SES } \\
\text { SES }^{2} \\
\text { FH }_{\mathbf{H}}(\%) \\
\text { FW }_{W}(\%) \\
\text { FY }_{\mathbf{I}}(\%)\end{array}$ & $\begin{array}{l}3028 \\
4.23 \\
0.2114 \pm 0.0361^{\mathrm{b}} \\
-0.0021 \pm 0.0005^{\mathrm{b}} \\
- \\
- \\
0.0331 \pm 0.0134^{\mathrm{a}} \\
0.0124 \pm 0.0144 \\
0.0159 \pm 0.0105\end{array}$ & $\begin{array}{l}1013 \\
4.28 \\
0.0766 \pm 0.0733 \\
-0.0001 \pm 0.0010 \\
-0.1270 \pm 0.0233^{\mathrm{b}} \\
0.0016 \pm 0.0009 \\
0.0939 \pm 0.0269^{\mathrm{b}} \\
0.0222 \pm 0.0248 \\
-0.0299 \pm 0.0207\end{array}$ & $\begin{array}{l}923 \\
5.01 \\
0.3290 \pm 0.0782 \mathrm{~b} \\
-0.0036 \pm 0.0011^{\mathrm{b}} \\
-0.0207 \pm 0.0582 \\
-0.0013 \pm 0.0030 \\
-0.0305 \pm 0.0186 \\
0.0270 \pm 0.0248 \\
0.0172 \pm 0.0160\end{array}$ \\
\hline
\end{tabular}

The mean is predicted for the year 1930, $\mathrm{SES}=8$, and $\mathrm{F}_{\mathbf{H}}=\mathrm{F}_{\mathrm{W}}=\mathrm{F}_{\mathbf{I}}=\mathbf{0}$. ${ }^{\mathrm{a}} p<0.05 ;{ }^{\mathrm{b}} p<0.01$.

since relatively more of these children will have achieved their twenty-first birthdays. Alternatively stated, the proportion of children at risk of death for 21 or more years born to parents married in the years 1920-1939 is greater than for children born to parents married at anytime between 1900 and 1964 . Note that within the former years "net fertility" is not significantly related to either maternal inbreeding or consanguinity. The absence of a maternal inbreeding effect is not unexpected since maternal inbreeding has not significantly and consistently affected total pregnancies or total livebirths.' With regard to consanguinity, it is clear that the increased mortality of liveborn infants in the consanguineous marriage diminishes substantially the effect of the greater reproduction associated with such marriages. The role of paternal inbreeding in the determination of family size remains a perplexing one; clearly paternal inbreeding is somewhat less associated with "net fertility" than with total livebirths, but a significant association exists insofar as non-farm families are concerned. We are unable to account for the farm-nonfarm differences with respect to paternal inbreeding in particular, since there exists no similar heterogeneity in respect of consanguinity effects. One is tempted to assume that there exists unforeseen concomitant variation, possibly socio-economic or cultural in origin, but the nature of this variation has eluded us. 
Table 8a. An analysis of the relationship of "net fertility" to length of cohabitation, socio-economic score, the coefficient of inbreeding of husband and wife, $\mathrm{F}_{\mathrm{H}}$ and $\mathrm{F}_{\mathrm{W}}$, and of their issue, $\mathrm{F}_{\mathrm{T}}$. The data are restricted to Buddhist households. Unless otherwise stated, the entries are regression coetficients with their standard errors

\begin{tabular}{|c|c|c|c|}
\hline & All marriages & Nonfarm marriages & Farm marriages \\
\hline \multicolumn{4}{|c|}{ Years $1900-1964$} \\
\hline Number & 7809 & 3384 & 1499 \\
\hline Mean & 4.07 & 4.29 & 4.52 \\
\hline Year & $0.1540 \pm 0.0027 \mathrm{~b}$ & $0.1634 \pm 0.0044^{b}$ & $0.1789 \pm 0.0090^{b}$ \\
\hline Year $^{2}$ & $-0.0016+0.0000^{b}$ & $-0.0017 \pm 0.0001 \mathrm{~b}$ & $-0.0018 \pm 0.0002 \mathrm{~b}$ \\
\hline SES & 二 & $-0.1069 \pm 0.0174^{b}$ & $-0.1632 \pm 0.0438^{b}$ \\
\hline SES $^{2}$ & - & $0.0013 \pm 0.0007$ & $0.0062 \pm 0.0022^{b}$ \\
\hline $\mathrm{F}_{H}(\%)$ & $0.0405 \pm 0.0081^{b}$ & $0.0480 \pm 0.0137^{b}$ & $-0.0126 \pm 0.0145$ \\
\hline $\mathrm{F}_{\mathrm{W}}(\%)$ & $0.0302 \pm 0.0083^{b}$ & $0.0287 \pm 0.0126^{\mathrm{a}}$ & $0.0211 \pm 0.0169$ \\
\hline $\mathrm{F}_{\mathrm{I}}(\%)$ & $0.0465 \pm 0.0064^{b}$ & $0.0245 \pm 0.0107^{\mathrm{a}}$ & $0.0662 \pm 0.0122^{b}$ \\
\hline \multicolumn{4}{|c|}{ Years $1920-1939$} \\
\hline Number & 2476 & 932 & 673 \\
\hline Iean & 4.03 & 4.22 & 4.72 \\
\hline Year & $0.2413 \pm 0.04$ & 0.1470 & $0.4454=$ \\
\hline Year $^{2}$ & $-0.0024 \pm 0.0006^{b}$ & $-0.0011 \pm 0.0011$ & $-0.0052 \pm 0.0013^{b}$ \\
\hline SES & - & $-0.0846 \div 0.0240^{b}$ & $-0.0379 \pm 0.0912$ \\
\hline SES $^{2}$ & - & $0.0005 \pm 0.0009$ & $-0.0015 \pm 0.0041$ \\
\hline $\mathrm{F}_{\mathrm{H}}(\%)$ & $0.0354 \pm 0.0148^{\mathrm{a}}$ & $0.0927 \pm 0.0274^{b}$ & $-0.0573 \pm 0.0213^{b}$ \\
\hline $\mathrm{F}_{\mathrm{W}}(\%)$ & $0.0370 \mp 0.0158^{\mathrm{a}}$ & $0.0251 \pm 0.0258$ & $0.0585 \pm 0.0290^{\mathrm{a}}$ \\
\hline $\mathrm{F}_{\mathrm{I}}(\%)$ & $0.0419 \pm 0.0115^{b}$ & $-0.0182 \pm 0.0210$ & $0.0756 \pm 0.0186^{\mathrm{b}}$ \\
\hline
\end{tabular}

The mean is predicted for the year $1930, \mathrm{SES}=8$, and $\mathrm{F}_{\mathrm{H}}=\mathrm{F}_{\mathrm{W}}=\mathrm{F}_{\mathbf{I}}=0$.

${ }^{\mathrm{a}} p<0.05 ;{ }^{\mathrm{b}} p<0.01$.

\section{Discussion}

One of the first, if not the first suggestion that reproductive compensation might maintain a polymorphism was that of Fisher et al. (1944) in respect of the Rh locus. It has spawned a number of theoretical considerations as well as some efforts to collect data to test this speculation. While the theoretical arguments that compensation, more particularly over-compensation, could support the Rh polymorphism have become more robust (see Feldman et al., 1969), the data that compensation does occur in this instance remain unimpressive (Glass, 1950; see also $\mathrm{Li}, 1953$ ). The controversy over the situation with respect to the $\mathrm{Rh}$ locus has, in our estimation, obtunded wider recognition of reproductive compensation as a means to maintain genetic variability or at least to dampen the rate of its reduction. The opportunities appear enormous. First, whether the culture be primitive or advanced, the bulk of pre-reproductive mortality has been and continues to be deaths in the first year of life. Second, there is a growing body of evidence that there exists a post-parturient period of infertility or non-susceptibility to conception whose duration depends in part upon the nature of the pregnancy termination, that is, whether a fetal death (abortion or stillbirth), a livebirth that dies within a year, or a livebirth that survives the first year of life. In the case of livebirths, breast-feeding can induce anovulatory periods the number 
of which changes in the event of the infant's death and cessation of nursing. These observations constitute the basis for rather elaborate models of human reproduction (Perrin and Sheps, 1964). Third, mean family size remains small when contrasted with man's apparent reproductive potential even in highly prolific groups such as the Hutterites. Thus, there would appear to exist unused reproductive potential which could be mobilized if circumstances demanded.

As stated at the outset, the case for reproductive compensation set forth here is circumstantial. It can be made somewhat more secure. Thus, analysis with smaller geographic units of the city and with additional concomitant variables including a variety of possible interactions reveals the same picture - a fact which is reassuring to say the least. We are presently examining the variances in total pregnancies, livebirths, and "net fertility" as they relate to inbreeding and consanguinity. It is also possible and relevant to examine birth intervals as functions of previous outcome as well as consanguinity and inbreeding. While these alternatives and others not enumerated may make this case more convincing, it will still remain to be shown how widespread the phenomenon may be. We have published data elsewhere which agree with those here presented (Schull et al., 1962), but these data also stem from Nagasaki Prefecture and we can not be sure that the phenomenon applies to other areas of Japan. The investigations of Tanaka et al. (1964) and Tanaka et al. (1967) in Fukuoka and Kumamoto Prefectures in Kyushu suggest that it may. In the final paper in this series we shall explore further some of the implications of reproductive compensation with respect to the maintenance of genetic variability.

\section{References}

Bodmer, W. F., Edwards, A. W. F.: Natural selection and the sex ratio. Ann. hum. Genet. 24, 239-244 (1960).

Edwards, A. W. F.: The limitations of population models. Proc. II. Intern. Cong. Human Genet. (Rome) $222 \quad \mathbf{2 2 3}$ (1961).

Feldman, M. W., Nabholz, M., Bodmer, W. F.: Evolution of the Rh polymorphism: A model for the interaction of incompatibility, reproductive compensation, and heterozygote advantage. Amer. J. hum. Genet. 21, 171-193 (1969).

Fisher, R. A.: The Genetical Theory of Natural Selection, pp. X and 291. Oxford: Clarendon Press 1930.

- Race, R. R., Taylor, G. L.: Mutation and the Rhesus reaction. Nature (Lond.) 158, 106 (1944).

Furuno, K.: Kakure kirishitan, pp. 201. Tokyo: Nihon Rekishi Shinsho 1959.

Glass, B.: The action of selection on the principal Rh alleles. Amer. J. hum. Genet. 2, 269-278 (1950).

Haldane, J. B. S., Jayakar, S. D.: The solution of some equations occurring in population genetics. J. Genet. 58, 291-317 (1963).

- - Selection for a single pair of alleles with complete replacement. J. Genet. 59, 171-177 (1965).

Li, C. C.: Is the Rh facing a crossroad? A critique of the compensation effect. Amer. Nat. $87,257-261(1953)$.

Perrin, E. B., Sheps, M. C.: Human reproduction: A stochastic process. Biometrics 20, 28-45 (1964).

Schull, W. J.: Inbreeding effects on man. Eugen. Quart. 6, 102-109 (1959).

- Komatsu, I., Nagano, H., Yamamoto, M.: Hirado: Temporal trends in inbreeding and fertility. Proc. Nat. Acad. Sci. (Wash.) 59, 671-679 (1968). 
Schull, W.J., Nagano, H., Yamamoto, M., Komatsu, I.: The effect of parental consanguinity and inbreeding in Hirado, Japan: I. Stillbirths and pre-reproductive mortality. Amer. J. hum. Genet. (in press) (1970).

- Neel, J. V.: The Effects of Inbreeding on Japanese Children, pp. XII and 419. New York: Harper and Row 1965.

- Yanase, T., Nemoto, H.: Kuroshima: The impact of religion on an island's genetic heritage. Hum. Biol. 34, 271—298 (1962).

Stern, C., Charles, D. R.: The Rhesus gene and the effect of consanguinity. Science 101, $305-307(1945)$.

Taeuber, I.: The Population of Japan, pp. XVIII and 461. Princeton: Princeton University Press 1958.

Tagita, K. P.: Showa jidai no senpuku kirishitan, pp. 491. Tokyo: Nihon Gakujitsu Shinkokai 1954.

Tanaka, K., Ohtsuki, N., Furusho, T.: Effects of maternal inbreeding on prenatal deaths in man. Proc. Jap. Acad. 43, 801-806 (1967).

- Yanase, T., Furusho, T.: Effects of inbreeding on fertility in man. Proc. Jap. Acad. 40, $852-856(1964)$.

Prof. W. J. Schull

Department of Human Genetics

University of Michigan

1137 E. Catherine Street

Ann Arbor, Michigan 48104

U.S.A. 